\title{
Can the Assessment of Quality of Life be a Landmark in Development of a Region? ${ }^{1}$
}

\author{
Larisa A. Novopashina* and Irina P. Vorontsova \\ Siberian Federal University \\ 79 Svobodny, Krasnoyarsk, 660041, Russia
}

Received 14.09.2014, received in revised form 19.10.2014, accepted 24.11.2014

This article discusses that the institutional conditions are not specified and are not open to the interaction of different social and industrial groups. We revealed the possibility of a multidisciplinary approach in the evaluation of quality of life. The study found that the area of attitude is the most representative. It is not important what is included in quality of life it is important what qualities affect behaviour. The study found that the life factors may affect the assessment of the quality of life, but it is not to influence behaviour of the population.

Keywords: external and internal factors, behaviour groups.

Research area: psychology.

\section{Introduction}

The article discusses the results of the interdisciplinary research on the problems of the territorial policy of the state in relation to the Siberian and Arctic regions.

Theorists of the Club of Rome in the search for solutions to global problems in 1970 came to the conclusion that the success or failure of economic, social and any other development ultimately depends on the level and the deployment of human resources.

The role of institutional constraints is shaping the conditions of capitalization of human potential as a factor in its implementation (by the criterion of effectiveness).

As part of the human potential of the game metaphor society corresponds to the composition of a team. Exodus team depends on the number and qualifications of the players who know the rules of the game well and enough to play to win. Accordingly, a balance generation, education, health, as well as sociocultural characteristics of the population affecting its viability are important for the survival and sustainable development of the region's population.

The economy of Siberia and the Arctic zone causes a number of the following features of quality of life:

1. Environmental pollution territory of the settlement in conjunction with extremely severe climatic conditions and therefore unattractive part of the territory of Siberia and the Arctic areas of permanent residence. In most of the territories referred to the Arctic zone capital investments aimed at environmental protection and rational

(C) Siberian Federal University. All rights reserved

* Corresponding author E-mail address: nla@ippd.ru 
use of natural resources are intermittent in nature.

2. Habitat does not meet the requirements of the medium of permanent residence due to the specifics of the industrial development of the Krasnoyarsk Territory and the Republic of Yakutia, which happened often with the use of the shift method. The Krasnoyarsk Territory and the Republic of Yakutia are not formed from large cities (except Norilsk). Small towns and townships today are not able to provide a current standard of quality of urban life (a degree of development of telecommunications, market and household services, accessibility of other cultural and economic centres of the country and the world, offers a high level of differentiation of jobs and an access to higher education, and so on etc.).

3. Low accessibility of settlements.

4. Insufficient provision of basic social services: education, health, culture of indigenous peoples because of their way of life (many members of the indigenous peoples have preserved a nomadic way of life). As a result, the indigenous peoples are characterized by the low level of education (or lack of education), high infant mortality, low life expectancy, a small set of consumed food and everyday products.

5. There is a high level of differentiation of the accumulated wealth, which in turn, is limiting factor mobility.

6. Low quality of social services available on the Arctic zone as a result of deterioration of quality staff of the social sectors of these areas.

A total increase in population of the Krasnoyarsk Territory largely depends on the migratory movement of the population compared to the Siberian Federal District as a whole. Analysis of the reproductive characteristics of the population leads to the conclusion that the expanded reproduction of the population is characterized by the Republics of Tuva and Altai.
In the last position: the Krasnoyarsk Territory and Novosibirsk Region - due to the low values of the urban population, Kemerovo and Tomsk Regions - due to low levels of all types of settlement population.

In terms of subjects of the Siberian Federal District, the closest structure of mortality by cause of death to the overall Novosibirsk Region is characterized by structural differences that can be stated in the national-territorial formations. Data of the SFD is primarily characterized by high mortality from external causes of death dominated by men suicide.

Traditional approaches to the development of human capital in the region, increase of quality of life, as reflected in the strategies developed by the social and economic development of the federal districts and subjects of the federation of municipalities do not give a positive effect on labour investment projects in the territory of Siberia and the Arctic zone due to a number of reasons:

Firstly, they do not take into account the effect of motivational, psychological and behavioural aspects of society shifts that are now shaped by global processes and information accessibility.

Secondly, the acting management paradigm of territorial development of the country, the mechanisms of interaction between government, business and the public areas, including the indigenous peoples of the North, do not provide equal benefits to the public from natural resources and actually perpetuate colonial-type resource development regions, which leads to a social degradation and a fall in the quality of life of the population.

\section{Methodology}

We have taken a step in the expansion of the resource capacity of economists by research tools of social psychologists, for example, economic studies based on mathematical methods. In 
recent decades, the analysis of the initial position and the forecast of socio-economic development only allowed the increase of the scope and completeness of calculations. From the standpoint of social psychologists working in cooperation with economists, it was important to resolve issues related to the integration of monitoring the quality of life based on the methods of social psychology in the system of territorial administration.

Today, profitable labour large investment projects in the region are a serious problem labour shortages are not only structural, but also absolute. At the same time, the population is to be expected to demonstrate irrational behaviour: the high rates of the standard of living in the region (most of the indicators of living standards among the leading Siberian regions and one of the eight leaders of Russian regions in the HDI), while the population of working age actively leaves its territory making a good career outside the region. At the same time, it should be noted that for the socio-economic development of the region the population mobility, especially in career, should be significantly higher than today's. However, the structure of migration outflows and inflows should contribute to the implementation of the region as an ongoing business and investment projects in the territory.

Such economy municipalities as the Krasnoyarsk Territory in Siberia and the Arctic zone are a different industrial type of management with a strong single-industry. The strategic directions of development of the regional economy can be formed on the basis of large-scale investment projects, building exportoriented resource sectors on the basis of modern technology, providing increased efficiency of factors of production, primarily of human labour. A number of countries (Canada, Australia and Norway) have experience of effective economic development on the basis of the resource sectors, and their development has become a real basis for the economic and social prosperity of the territory where they are located.

In addition, recent years have been characterized by the following trends in the evaluation of the quality of life:

Firstly, the government established a framework for the development of the quality of life.

Secondly, awareness of the need for the special migration policy aimed at attracting young, highly qualified personnel to ensure sustainable development of the territory.

Thirdly, there is a change in the criteria for the evaluation of regional authorities according to the Decree of the President of the Russian Federation, where a subjective assessment of satisfaction with residents' health and education services was added.

In this regard, the formation of a human capital and a new management model of the quality of life in the regions require reflection, along with the economic, investment and financial factors of socio-psychological and institutional aspects.

Currently, there is a large number (about 60) of different methods assessing the quality of life, using thousands of indicators of human life in society as a whole and its individual sectors. However, most of these techniques are objective in nature, given the weak subjective attitude of people to the quality of life, and secondly, are designed to match the level and quality of life in different regions and countries, but not adapted to control.

Thus, the standard approaches to the study of quality of life based primarily on objective indicators need to be improved by incorporating sociological and psychological factors characterizing attitude of the population to the existing format of the environment and the motivation of the decision on relocation. This will provide a more comprehensive information 
strategy for the development of the human potential in the region.

We assumed that the dynamics of the behavioural patterns of major groups can determine the effectiveness of management decisions to design and predict the development processes. We believe that objectified factors (age, economic, social factors) and the idea of them do not determine behaviour directly. Behaviour is influenced by internal factors that, in turn, form personal resource capabilities of decision making and implementation. [2]

\section{Participants of the research}

Research participants were from different groups: population, government representatives, and representatives of business, production and social sphere. The study was conducted in four stages.

At the first stage, characteristics of the quality of life were identified taking into account various professional (sociological, economic, psychological, organizational, etc.) approaches. Thus, an analysis of existing international and Russian studies was carried out. Highlighted characteristics were grouped into meaningful factors that represented employment, education, health, habitat and family.

The next step is a method of expert estimates with isolated groups of people, attitudes, opinions and representations that are indicators for the adoption of decisions. So we identified three groups. They are representatives of the authorities, the actual population and representatives of business and professional groups that implement business behaviour. We proceeded from the assumption that the behaviour of active business people is crucial and affects the behaviour of other social groups.

At the second stage, there were factors of quality of life that affect the behaviour of business people (representatives of small and medium- sized businesses). Thus, we divided focus groups. The first group with representatives of business is called "Business". The second group includes business people and is called "Production workers".

The third group was people from social service, including representatives from the social sector.

The choice of such participants is due to the need to identify the characteristics of the quality of life affecting decision-making in business and professional groups. The objective of this step was the selection of quality of life influencing the behaviour of people showing business activity and retention factors of professionals in the Territory.

Focus group interviewing allows us to detect the submission of such characteristics of the quality of life that contribute to active, passive, protest behaviour.

We studied views and opinions on the quality of life of the population in the third stage. We proceeded from the assumption that there is a set of factors that determine the migration/ immigration behaviour. To this end, an opinion poll was conducted to study the representations of the public about the content of the concept of "quality of life" and its evaluation in accordance with defined views.

The questionnaire was to explore ideas about the quality of lifestyle, environment, safety of life, health, education and upbringing of new generations of business, government, etc. The questionnaire contained 55 questions, including socio-demographic data. In total 1409 respondents from cities of the Krasnoyarsk Territory were interviewed.

At the fourth stage, we studied representations of power on the representations of the population and the quality of life factors, reasons, the decision of various groups to change address and business activity. The studied 
group included representatives of legislative and executive power.

\section{Discussion}

As a result of the focus groups, it was found that the participants of the "Business" minded isolated factors such as the quality of life of medicine, education, security of business, peace of mind, for targets in the territory, having a job.

According to the focus group participants, the main component of this concept is "to have a job like a man" and "all other factors already follow from this". Most of the interviewees identified the concept of quality of life as the presence of a coherent set of "to live, work, relax".

According to the participants, a set of characteristics that describe a "suitable place to live" is composed of a more complete list, namely a geographical location, natural conditions, population density, degree of monopoly; vertical of power, legislation, tax burden, number of regulatory bodies, distribution mechanism in the region, level of staff, speed communications. The most common characteristic of this group is interested in the power of business and industry.

Highlighting the factors that lead to protest behaviour or migration trends the focus group participants noted the deficit of jobs, lack of training, lack of consumers, low opportunity areas across the country, lack of infrastructure. When answering this question, the maximum number of matches is among the factors of the deficit of jobs and the lack of infrastructure.

During the analysis, it was found that the dominant factor in business prospects and is the loss of relevance of business in the region.

The focus group participants of the "Production" in their perceptions of the quality of life represent security, cultural environment, healthy environment, satisfaction with the provision of social services, access to education and quality of food.
The most important component of the concept of "quality of life" has become a "satisfaction provision of social services".

According to the "Producers", the characteristics of a "suitable place to live" are: the availability and quality of education; availability and quality of medicine; security (a low crime rate); quality and cost of housing; ecology; provision of kindergartens; availability of recreation for children and adults; prestige sociocritical occupations; socio-cultural environment; convenient means of transport; qualified professionals; possibility of self-realization; wages. The most important characteristic is the quality and accessibility of education in the region.

According to the focus group participants, the following factors cause protest behaviours: poor environment and natural disasters; technical or industrial disasters; high levels of unemployment; excessive migration (dominance of other nationalities); low wages; low level of social and cultural environment; excessive density of development of the city; excessive administration (bureaucracy, high taxes, etc.); tragic events in family life; persecution. A significant factor, according to the "Producers" is the factor of a "bad environment and natural disasters". The group identified the dominance of the factors of the future, in particular career prospects.

In the view of the focus group participants, the "Social services" includes: stability in the surrounding social environment; stability in salary, food, accommodation; satisfaction with the provision of social services; environment; level of culture and education; sense of fairness; availability of opportunities of development and freedom; material standard of living; presence of a positive outlook. The main components of understanding the quality of life are: satisfaction with the provision of 
social services; environment; level of culture and education.

Description of the place suitable and desirable for living is represented by the following characteristics: quality of housing, quality of food, security, environment, health, provision of services, wages, territory, freedom, culture, national factor, possibility of self-realization and professional development, access to education [3, 4]. The most prominent factors are the provision of services, the opportunity for professional growth.

So, for the participants the following factors are principal: the artificial increase of prices in the region, the national factor, natural disasters in the territory, and the emergence of economic opportunities. Members of this group are guided by such factors as material wealth and the availability of future opportunities for their children and grandchildren.

Thus, we have identified the main characteristics of the quality of life in the representations of the active set of the professional community and the consistency of these representations in the cluster.

We evaluated the differences in the expression of quality of life in the presentation of three profession groups (by the criterion $\chi 2$ ).

It was set that the agreed characteristics for the three groups are the notions of quality of life in general; the factors that lead to the action and/or the protest behaviour and the time factor. But the idea of a desirable place of residence is a pronounced mismatch.

This phase of the work showed that the main factors for a decision when choosing a particular behaviour in a cluster of business activity are: the lack of conditions (inability) to deploy business in the region; natural disasters and the "poverty" of the socio-cultural environment.

At the next stage of work we identified representations about the quality of life of the population. We proceeded from the assumption that there is a set of external factors, in relation to which the inner feelings, attitudes and well-being become defining factors of the migration/immigration behaviour. These factors include: income, education, health, security.

As a result of the opinion poll we revealed public presentation of the content of the concept of the "quality of life" and its evaluation in accordance with the defined views.

The questionnaire was to explore ideas about the quality of lifestyle, environment, safety of life, health, education and upbringing of new generations, business, government and so on.

The data showed that for the population the main factors are a state of health, satisfaction with their lives, and only then material wellbeing, the availability of apartments, free time, personal, family and working safety. Figure 1 shows the most important qualities of life, in terms of population, obtained in the course of a sociological survey.

In the next step, we revealed opinions of the authorities of the settlements on the quality of life. To solve this problem we were interviewed 21 representatives of the legislative and executive branches.

The results showed that the parameters of the quality of life, according to the authorities, differ from the views of the population on the quality of life to a greater extent; they mentioned such factors as the level of income, the level of tariffs, access to education and health care. At the same time, the participants noted subjective (internal) factors, such as a feeling of comfort and security.

Most interviewees discussing the question of quality of life in the settlements allocated different categories, characteristics and parameters of representations. These categories included: 
youth, seniors, working-age population, and entrepreneurs. They were allocated according to the specificity of representations of gender and class positions (poor, middle class, high level of income).

According to the authorities, when characterizing the quality of life the population mainly deals with living conditions.

Then we ranged characteristics perceptions of quality of life in power. The external power indicator objectively reflects the following criteria: demographic, material factors, facilities, programs, social support, mortality, introduction of high-tech (cardiological, perinatal and cancer centres), level of welfare of the population, level of wages, raising additional revenue, development of industrial infrastructure, level of unemployment, environment, appearance of the city, human ecology.

We specially asked about the circumstances and causes of migration behaviour. According to their responses we allocated different types of migration - labour and political. These groups include: youth, working population and entrepreneurs. In addition, experts distinguish between external and internal migration (for example, when a person stops working while actually being in the workplace). One-third respondents said that migration is a natural human desire to live and work where it is best for them.

The main reasons for the decision are set out below. According to the experts, these reasons are (the data is presented in order of importance):

- Living conditions - work, family life, leisure, self-realization;

- Work and income, career;

- Ecology;

- Forfeiture of something, for example, social benefits or privileges;

- Living conditions in another region are much better;
- Changing the status of a citizen graduation from high school, admission to college, marriage, etc.;

- More comfortable living environment;

- Injustice in residence;

- Business conditions;

- Level and ratio of income;

- Guarantee of future results;

- Low qualifications;

- Homelessness;

- Income gap among population groups;

- Higher prices for essentials;

- Risks to the capital - poor infrastructure, logistics system, conditions;

In addition, the experts identified internal (subjective) reasons. Among them are:

- Sense of hopelessness;

- Party (club);

- Health status;

- Internal inconsistencies with the expectations.

Thus, the analysis found that it is possible to distinguish between labour and political migration, which, in turn, may vary as internal and external, active and passive. For each of the types of migration there is a set of external and internal factors of the quality of life that define a particular behaviour and its dynamics.

According to the experts, the overall quality of life has external and internal factors of representations from the public. And first of all, the population is focused on the external factors, and then to the internal ones.

Power efficiency is estimated by the population primarily in the characteristics of the external factors, which are demographic, material factors, facilities, programs, social support, mortality, and introduction of high-tech, the level of welfare of the population, the level of wages, raising additional revenues, development of industrial infrastructure, unemployment, environment, and appearance of the city. 
Next, we performed a comparative analysis of the performances of different groups, participants in the study, which showed that the idea of the quality of life in power, people with business activity and population strongly mismatched [1].

\section{Conclusion}

Thus, we have used the possibility of a multidisciplinary approach to overcome the traditional limits of growth (both in terms of a research paradigm and its performance in terms of incorporating the results into practice administration of the territory).

It was found that the most representative area is the area of relations; we also found what qualities emerge as influencing behaviour. It was noted that the population may have a different factor, but is willing to tolerate, in other words, to assess the quality of life impact, and the behaviour is not affected.

The study also revealed that the assessment methodology should take into account the age factor. For example, the youth refers to the quality of life through the possibilities and perspectives of parents.

In the next age group (those who entered the labour market), the quality of life is determined by the possibility to realize themselves as a subject in civil, economic and political context.

The potential of the next generation is characterized by assessing the top of life and manifests itself in the experience of the possible contribution to future generations.

Due to the fact that the idea of the quality of life in the power-population groups "Business" - is strongly misaligned, and the government believes that the other two groups, first of all, take into account external factors, it is necessary to work out the institutional environment organizing, for example, areas of public consent.

It was found that the institutional conditions are not set out and not open to the positing and detection of visions of groups. In this sense, the decisions taken on the quality of life are in the nature of action, and do not reflect the interaction. In other words, it was found that in the assessment of quality of life, it is important to take into account the lower threshold characteristics backed by the meaning of the impossibility of the further action expressed in the everyday language as "cannot live on". Currently, there are only upper threshold characteristics, which, in the everyday language, imply the question "how do you want to live?" and how to keep up with the expectations of the impossible.

In the context of the issues and objectives of the research we have identified factors that affect the quality of life and developed an approach to the refinement of the threshold characteristics that "force" people to make crucial decisions and "move" to another place of business and life.

\footnotetext{
The study was sponsored by the RHF research project "Methodological approaches to modeling of the control and monitoring of the quality of life of the population of Siberian regions, including the Arctic zone, to form a differentiated spatial policy of the country", No. 13-12-24011.
}

\section{References}

1. Bukharova, Evgenia B., Lapo, Valentina F., Vorontsova, Irina P. A Spatial Structure of Investment and Population Settlement in the Krasnoyarsk Territory: do they Correspond to Each Other? Journal of Siberian Federal University. Humanities \& Social Sciences 01 (2012 5).

2. Novopashina, Larisa A.; Khasan, Boris I. Conflict Situation and its Manifestation in Assessment of Quality of Life. Journal of Siberian Federal University. Humanities \& Social Sciences, April 2014 (volume 7, number 4) pp. 597-608; 
3. Novopashina, L., Vorontsova, I., Quality Rating of Life. The Possibilities of Interdisciplinary Research. 4th International Conference on Science and Technology. June 25-26, 2014, Scieuro Publishing 2014

4. Vorontsova Irina P., Samylkina Tatiana A., Pozdeev Alexander N. Evolution of a Large-Scale Agglomeration Labour Market (Based on the Example of the Krasnoyarsk Agglomeration). Journal of Siberian Federal University. Humanities \& Social Sciences 10 (2012 5).

\title{
Может ли оценка качества жизни \\ быть ориентиром для развития региона?
}

\author{
Л.А. Новопашина, И.П. Воронцова \\ Сибирский федеральный университет \\ Россия, 660042, Красноярск, пр. Свободный, 79
}

В настоящей статье ведется обсуждение того, что институциональные условия не определены для взаимодействия различных сочиальных и промышленных групп. Мы выявили возможность междисциплинарного подхода в оценке качества жизни. Исследование показало, что сфера отношения является наиболее характерной. Не важно, что именно включает в себя качество жизни, важно то, какие качества влияют на поведение человека. Ключевые слова: внешние и внутренние факторы, поведенческие группы.

Научная специальность: 19.00.00 - психологические науки. 